\title{
Diurnal Variation in Glucose Tolerance and its Reversal by Lengthened Fasting
}

\author{
P. M. TRENCHARD, R. D. JENNINGS
}

British Medical fournal, 1974, 2, 640-642

\section{Summary}

In a group of healthy young male volunteers a worsened tolerance to oral glucose in the afternoon after a fourhour fast was reversed by a 12-hour fast. The latter also produced consistent mild hypoglycaemia from two and a half to four hours after the glucose loading irrespective of the time of day.

\section{Introduction}

Diurnal variation in oral glucose tolerance has been observed by many workers (Hayner et al., 1965; Bowen and Reeves, 1967; Freinkel et al., 1968; Rigas et al., 1968; Jarrett and Keen, 1969, 1970; Hansen and Johansen, 1970; Jarrett et al., 1972). The most consistent finding from the work of Jarrett et al. (1972) and Jarrett and Keen (1969, and 1970) on normal subjects was a significant worsening of afternoon tolerance to oral glucose one, one and a half, and two hours after loading. They used a ninehour fasting regimen with two-hour glucose tolerance tests at 09.00 and 15.00 hours and sampled capillary blood (Jarrett et al., 1972). We feel that such a variation can be described as truly diurnal only if major fasting effects are shown to be absent -that is, if tests using four-hour and 12-hour fasting regimens yield virtually identical results. The experiments described here examine some of the possible effects of different fasting regimens on this "diurnal" variation.

\section{Methods}

Fit men aged 22 to 24 years with no immediate family history of diabetes mellitus volunteered for the study. A daily carbohydrate intake of 200 to $300 \mathrm{~g}$ was ensured for three days before testing. All blood samples were venous and were obtained from an indwelling antecubital venous cannula inserted with minimal trauma one hour before sampling began. Rest was absolute from the time of cannula insertion to the end of the tests. Cannula patency was maintained by the injection of 1 unit of heparin in 1 $\mathrm{ml}$ of saline every 10 minutes. Blood for glucose estimation was taken direct into tubes containing fluoride; plasma was separated and used to estimate sugar by the method of Moore et al. (1972). All glucose tolerance tests lasted four hours and were begun at 09.00 and 13.00 hours. The $50-\mathrm{g}$ glucose loads were given as $182-\mathrm{ml}$ aliquots of Boots Sparkling Glucose Drink (glucose syrup $28 \%$, citric acid $0.2 \%$, lactic acid $0.1 \%$, benzoic acid 600 p.p.m.). The following sampling and fasting regimens were used.

Type $A$, equalized "short-fast" regimen (four-hour fast/ four-hour fast).-Eight subjects participated, being woken at 05.00 hours on the day of the test to drink $50 \mathrm{~g}$ of liquid glucose. \footnotetext{
Department of Chemical Pathology, Bristol Royal Infirmary, Bristo
BS2 8HW

P. M. TRENCHARD, M.B., B.sC., Registrar in Pathology

R. D. JENNINGS, M.A., A.R.I.C., Senior Biochemist
}

Subsequent 50 -g oral loads were given at 09.00 and 13.00 hours. Sampling times were given as follows: 09.00 (before glucose load), $09.30,10.00,10.30,11.0012 .00,13.00$ (before glucose load), 13.30, 14.00, 14.30, 15.00,16.00, and $17 \cdot 00$ hours.

Type B, "physiological " fasting regimen (12-hour fast/fourhour fast).-Nine subjects participated. Food was prohibitedwithout standardizing the last meal-from 21.00 hours on the day preceding the test. A $50-\mathrm{g}$ glucose load was given at 09.00 and 13.00 hours. Sampling was carried out as for type A but with additional samples being taken at 11.30 and 15.30 hours.

Type C, equalized "long-fast" regimen (12-hour fast/12-hour fast). - Eight subjects who had undergone the type $B$ regimen returned the next day having fasted from 01.00 hours-without standardization of the last meal. The glucose load was given at 13.00 hours with sampling as for the type B afternoon curve. Normal caloric intake was ensured for the type $B$ test day as a whole by appropriate evening feeding, while activity during the morning of the type $\mathrm{C}$ test day was made minimal.

Points were compared statistically by applying Student's $t$ test to the mean values. All points quoted here as being significantly different had $P$ values of less than 0.05 .

\section{Results}

Both morning curves (type A, four-hour fast/type B, 12-hour fast) peaked at half an hour and showed no points of significant difference (fig. 1).

The two afternoon curves which followed a four-hour fast (types A and B) showed no significant difference at any time. They differed from the morning curves in that their peaks occurred at one hour.

The afternoon curve after a 12-hour fast had its peak at half an hour, with a value apparently lower than any of the other

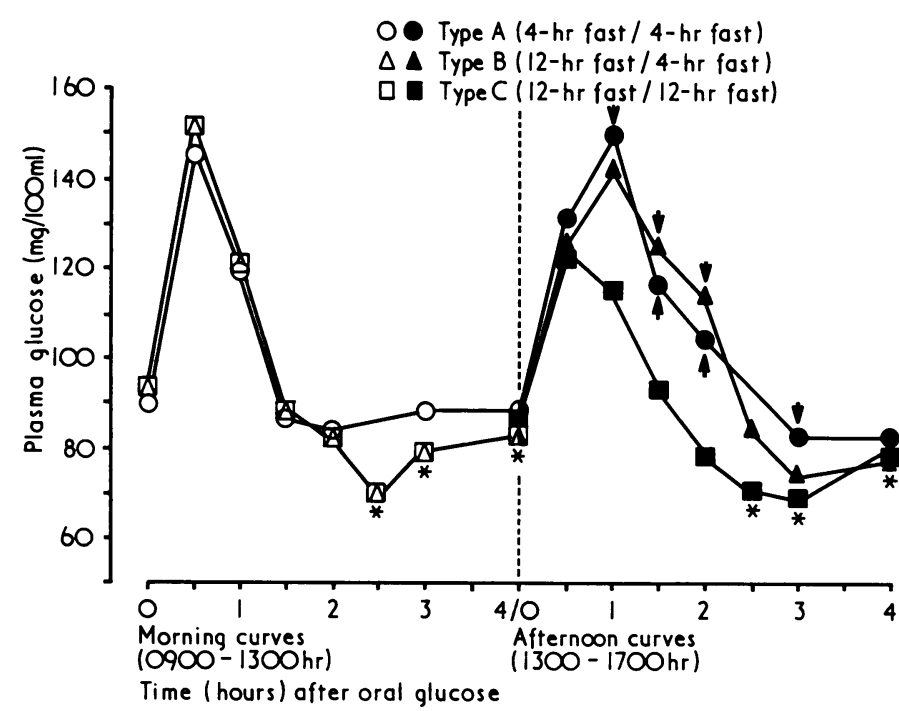

FIG. 1-Glucose responses of types A, B, and C during day. Arrows indicate type $A$ and $B$ values which differed significantly $(P<0.05)$ from those of type C. Symbols marked with asterisk denote values that lay significantly $(P<0.05)$ below zero time value (fasting) for that curve. There were no $2 \frac{1}{2}-h r$ values for type A. 
peaks. It thus resembles the other morning curves rather than the other afternoon curves, the points of significant difference from the latter being shown in fig. 1.

The two-and-a-half to four-hour portions of those curves which followed a 12-hour fast (type B morning and type C afternoon) lay significantly lower than the respective fasting value-that is, the curve "overshot" ("late reactive hypoglycaemia").

\section{Discussion}

When evaluated over the eight-hour period there was no significant difference between the type $A$ and type $B$ curves. The morning curves, however, differed significantly from the afternoon curves. This was best shown by superimposing, for each type in turn, the morning curve on the afternoon curve (figs. 2, 3, and 4). This is the method already used by most workers for describing and calculating the presence and significance of diurnal variation. For type A (four-hour fast/ /four-hour fast) this showed relative afternoon intolerance at

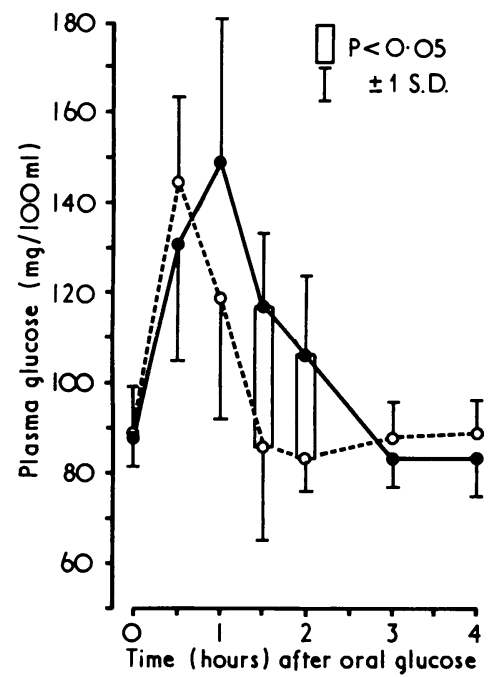

FIG. 2-Morning (0) and afternoon (O) glucose responses of type A (four-hour fast/four-hour fast)

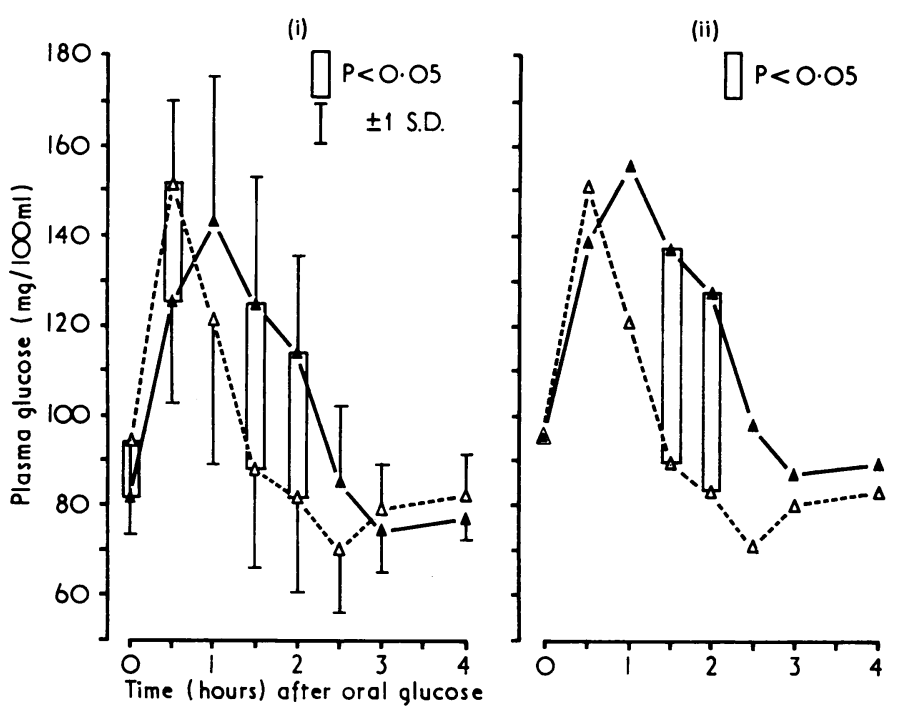

FIG. 3-Morning $(\triangle)$ and afternoon $(\Delta)$ glucose responses of type $B$ (12hour fast/four-hour fast). (i) Experimental observation. (ii) With afternoon response raised by $12.5 \mathrm{mg} / 100 \mathrm{ml}$ (zero time morning/afternoon difference). (i)

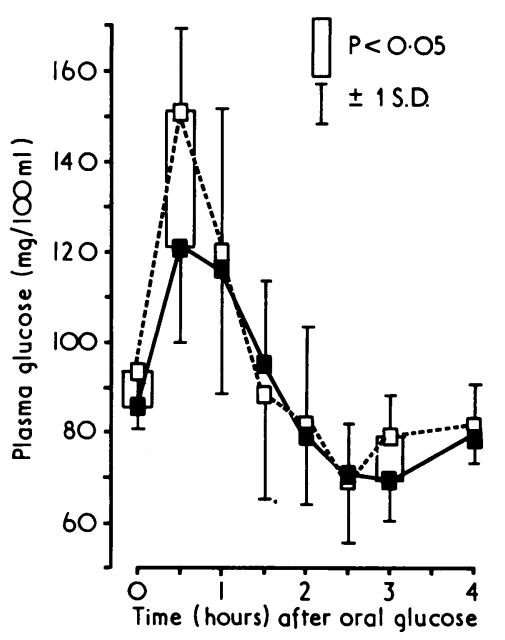

(ii)

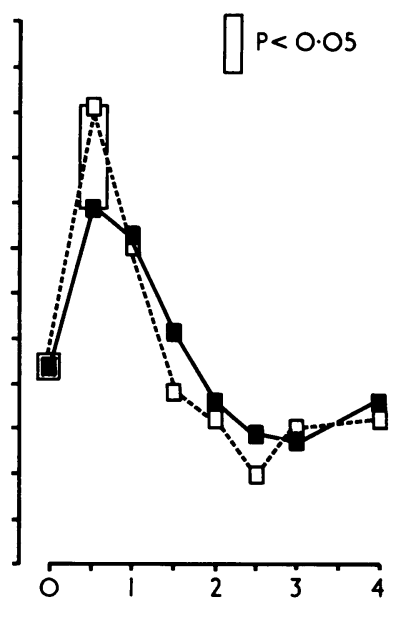

FIG. 4-Morning $(\square)$ and afternoon ( $\square$ ) glucose responses of type $\mathbf{C}$ (12hour fast/12-hour fast). (i) Experimental observation. (ii) With afternoon response raised by $7.5 \mathrm{mg} / 100 \mathrm{ml}$ (zero time morning/afternoon difference).

one and a half and two hours only (fig. 2). This correlated well with the "diurnal" findings of Jarrett et al. (1972) and Jarrett and Keen $(1969,1970)$ even though a shorter fast length, an earlier afternoon test, and venous sampling were used in this study. For type B (12-hour fast/four-hour fast) such superimposition gave afternoon intolerance identical with that of type A (fig. 3). There was, however, relative afternoon hypoglycaemia at zero and half an hour and significant late reactive hypoglycaemia occurred during the type B morning test. This phenomenon preceded the type $B$ afternoon test and was therefore responsible for the relative afternoon fasting hypoglycaemia. This might, then, have caused the whole afternoon curve to be "set" at a lower level, thereby accounting also for the afternoon half-hour hypoglycaemia. When the whole afternoon curve is raised by an amount equal to the fasting difference (fig. 3 (ii)) the above-mentioned relative afternoon hypoglycaemia becomes insignificant whereas the later afternoon intolerances are enhanced. Thus the type $B$ afternoon curve was virtually identical in shape with that of type A but was set at a lower level, presumably due to the preceding hypoglycaemia.

When the type $C$ afternoon curve was superimposed on the morning (type B) curve no relative afternoon intolerance was observed (fig. 4). Instead there were three points of relative afternoon hypoglycaemia at zero, half an hour, and three hours. When the afternoon curve is raised by an amount equal to the fasting difference, as was done for type $B$ (fig. 4 (ii)), then the only remaining relative afternoon hypoglycaemia is at half an hour. These factors imply that the type $\mathrm{C}$ afternoon curve is set at a lower level but with an additional lowering of its half-hour point far in excess of this general lowering. Such is unlikely to be due to any preceding physical activity during the morning as this was kept to an absolute minimum. The implication instead is that a long fast before an afternoon test gives it the general shape of the other morning curves with a noticeably lowered peak height and a mild lowering of the curve as a whole. The net result of this, then, is not to abolish the "diurnal" variation described above for types A and B but rather to reverse it.

\section{Conclusions}

The results obtained show (1) the existence of a relative afternoon intolerance when the afternoon test is preceded by a fourhour fast; (2) improvement of glucose tolerance in afternoon tests preceded by a 12 -hour fast, thereby reversing the "diurnal" effect normally observed; and (3) that "late reactive hypogly- 
caemia" is consistently produced after a 12-hour fast irrespective of the time of day.

We wish to thank Dr. G. K. MoGowan for his advice and helpful comments.

\section{References}

Bowen, A. J., and Reeves, R. L. (1967). Archives of Internal Medicine, 119, 261.
Freinkel, N., Mager, M., and Vinnick, L. (1968). Fournal of Laboratory and Clinical Medicine, $71,171$.

Hansen, A. P., and Johansen, K. (1970). Diabetologia, 6, 27.

Hayner, N. S., Kjelsberg, M. D., Epstein, F. H., and Francis, T. (1965). Diabetes, 14, 413.

Jarrett, R. J., and Keen, H. (1969). British Medical fournal, 2, 341.

Jarrett, R. J., and Keen, H. (1969). British Medical fournal, 2, 341 .

Jarrett, R. J., Baker, I. A., Keen, H., and Oakley, N. W. (1972). British Medical fournal, 1, 199.

Moore, G. R., Barnes, I. C., and Pennock, C. A. (1972). Clinica Chimica Acta, 41, 439.

Rigas, A. N., Bittles, A. H., Hadden, D. R., and Montgomery, D. A. D. (1968). British Medical fournal, 4, 25.

\title{
Simultaneous Occurrence of Acute Myeloblastic Leukaemia and Multiple Myeloma without Previous Chemotherapy
}

\author{
THOMAS TURSZ, GEORGES FLANDRIN, JEAN-CLAUDE BROUET, JEAN BRIERE, \\ MAXIME SELIGMANN
}

British Medical Fournal, 1974, 2, 642-643

\section{Summary}

The simultaneous detection of multiple myeloma and acute myeloblastic leukaemia is reported in two patients who had not undergone chemotherapy. Histological examinations confirmed the infiltration by both myeloblasts and plasma cells. Only the latter contained monoclonal immunoglobulin chains at immunofluorescent studies. The possible relation between the two distinct proliferative processes is briefly discussed.

\section{Introduction}

The occurrence of acute myelomonocytic leukaemia or of acute myeloblastic leukaemia (A.M.L.) supervening on multiple myeloma (M.M.) (Kyle et al., 1970; Lancet, 1971) has now been recognized in about 30 patients who had undergone long-term chemotherapy with alkylating agents. The simultaneous detection of both M.M. and A.M.L. in previously untreated patients has not yet been described. It is thus of interest to report two such cases.

\section{Case 1}

A 77-year-old man was referred for a pancytopenia which had been discovered three years earlier. Physical examination showed nothing abnormal. Haemoglobin was $10 \mathrm{~g} / 100 \mathrm{ml}$; W.B.C. was $2,000 / \mathrm{mm}^{3}$ of which $44 \%$ were neutrophils and $55 \%$ were lymphocytes; the platelet count was $80,000 / \mathrm{mm}^{3}$ Bone marrow smears were hypercellular with $51 \%$ of peroxidase-positive myeloblastic cells and $23 \%$ of grossly dystrophic plasma cells. This picture was consistent with both M.M. and A.M.L.

The serum electrophoretic pattern showed a narrow spike $(1 \mathrm{~g} / 100$ $\mathrm{ml}$ ) which was identified as a monoclonal IgA $1 x$ on immunoelectrophoresis. The levels of IgG and IgM were greatly decreased. There was no proteinuria. The skeletal survey was normal.

\footnotetext{
Institut de Recherches sur les Maladies du Sang, H6pital SaintLouis, 75475 Paris

THOMAS TURSZ, M.D., Interne des Hôpitaux

GEORGES FLANDRIN, M.D., Chef de Travaux Assistant JEAN-CLAUDE BROUET, M.D., Chef de Clinique Assistant JEAN BRIERE, M.D., Chef de Clinique Assistant MAXIME SELIGMANN, M.D., Professeur d'Immunologie
}

The immunofluorescence study of the marrow cells with antisera to the various immunoglobulin chains showed that all the plasma cells contained alpha and kappa chains whereas the myeloblastic cells were negative for intracytoplasmic and membrane-bound immunoglobulins.

Postmortem examination showed a striking infiltration of the bone marrow and of the spleen by myeloblasts and plasma cells.

\section{Case 2}

A 74-year-old man had had a mild pancytopenia since 1967. Extensive haematological studies were performed in 1971. At that time physical examination showed nothing abnormal except a generalized purpura. Haemoglobin was $11 \mathrm{~g} / 100 \mathrm{ml}$; W.B.C. was $1800 / \mathrm{mm}^{3}$ of which $48 \%$ were neutrophils and $32 \%$ were lymphocytes; the platelet count was $60,000 / \mathrm{mm}^{3}$ Bone marrow smears were hypercellular with $51 \%$ of peroxidase-positive myeloblasts and $15 \%$ of plasma cells. A marrow biopsy showed an extensive invasion by both myeloblastic and plasma cells.

Serum electrophoresis disclosed a narrow spike $(2.5 \mathrm{~g} / 100 \mathrm{ml})$ which was identified on immunoelectrophoresis as a monoclonal IgG $\lambda$. The levels of polyclonal IgG, IgM, and IgA were very low. There was no proteinuria. Skeletal $x$-ray examination showed a mild osteoporosis. All plasma cells were shown to be strongly positive with antisera to gamma and lambda chains by intracytoplasmic immunofluorescence study whereas the myeloblastic cells were negative. Despite therapy with mercaptopurine the patient died a few months later. Necropsy was not performed.

\section{Discussion}

All previously reported patients in whom A.M.L. supervened on M.M. had been treated for 14 months to eight years with alkylating agents, mostly with melphalan. Many of these patients had also received local radiotherapy. A single patient reported by Videbaek (1971) had not been treated, but the diagnosis of A.M.L. seems very doubtful since the "blastic" cells were shown by immunofluorescence to contain immunoglobulin chains and were thus probably immature cells of plasmacytic origin, similar to those found in the patient reported by Thijs et al. (1970).

The leukaemogenic role of long-term chemotherapy is ruled out in our two patients. Other hypotheses should therefore be raised to explain the occurrence of both A.M.L. and M.M., and possibly the prolonged survival induced by therapy in M.M. patients may offer the opportunity to observe hitherto unrecognized aspects of the natural history of M.M. The humoral immune defect in myeloma may facilitate the emergence of other neoplastic clones. A common aetiological agent could be 